\title{
Diversity for Tree Growing Habit in the Natural Population of Indigenous soft pear in Jammu Province, India
}

\author{
Ambika Bhandari*, V.K. Wali, Amit Jasrotia, Mahital Jamwal, Kiran Kour, \\ Gurdev Chand, Vivak M Arya and V.K Razdan
} Division of Fruit Science, Faculty of Agriculture, Sher-e-Kashmir University of Agricultural
Sciences and Technology of Jammu, Chatha J\&K, India

*Corresponding author

\section{Keywords}

Pear, Diversity,

Tree vigour, Leaf shape

Article Info

Accepted:

25 May 2020

Available Online:

10 June 2020

\section{A B S T R A C T}

The present investigation entitled diversity for growth habit in the natural population of indigenous soft pear in the Jammu province was carried out in order to document the available genetic variability in pear germplasm and to select elite pear genotypes possessing superior attributes and quality traits. During the survey, data was recorded on sixty (sixty) soft pear trees growing in different areas of Doda and Kishtwar districts of Jammu province. Remarkable variability was observed in seedling pear trees for different morphological, and physical characters. Similarly, variations were also reported for other characters viz., tree vigour, tree habit, leaf size, and leaf shape and leaf margins. Studies on tree habit revealed substantial variability among the seedling raised pear genotypes. In this study it was found that out of 60 selections of soft pear 33 (43\%) had upright tree habit, while 19 selections (32\%) had spreading tree habit and rest of the 8 selections (25\%) had dropping tree habit. In case of tree vigour out of 60 selections of soft pear none of the selection had extremely weak tree vigour, while 1 selections (2\%) had weak tree vigour, 11 selections (30\%) had intermediate tree vigour, 33 selections (37\%) had vigorous tree vigour and rest of the 16 selections $(32 \%)$ had very vigorous tree vigour. Among sixty genotypes $6(10 \%)$ selections having small leaf size, while 32 selections $(53 \%)$ having medium leaf size and rest of the 22 selections (37\%) having large leaf size. In case of leaf shape 21 (35\%) selections ovate shape of leaf, $6(10 \%)$ selections ovate oblong shape of leaf, $31(52 \%)$ selections orbicular ovate shape of leaf, 1 (2\%) selections elliptic shape of leaf, and no selections had lanceolate shape of leaf. Out of 60 selections under study under study $8(13 \%)$ selections had entire leaf margins, none of selections had dentate leaf margins, 43 (72\%) selections had serrulate leaf margins and no selections had others margins of leaves. 


\section{Introduction}

The genus Pyrus belongs to the subfamily Pomoideae and family Rosaceae with a basic chromosome number of $\mathrm{x}=17$ and about 20 primary species proposed by Challice and Westwood (1973) are generally accepted by the most taxonomists. Pear stands 2nd after apples as the most frequently consumed fruit and the most economically important tree fruit in temperate zones of the world (Ahmed et al., 2011). In India, pear cultivars commercially grown belong to Pyrus pyrifolia and Pyrus communis group. The pears are widely grown in North Western Himalayan region including Jammu and Kashmir, Himachal Pradesh and Uttrakhand. In Jammu region, the area under pear is around 7630.00 ha with production of about 24789.00 MT (Anonymous, 2017-18). Pear is excellent source of carbohydrates, optimum quantity of sugars and dietary fiber (Blattny, 2003). Chemically they are mainly composed of carbohydrates. Different sugars, starch and cellulose are the main carbohydrate forms found in the pear fruits. In ripe fruits, sugars constitute about 70 percent of the total carbohydrates percentage. Fructose is the predominant sugar $(6.5 \%$ to $11.2 \%)$ followed by glucose $(0.5 \%$ to $3.5 \%)$ and sucrose $(0.1 \%$ to $2.4 \%$ ) in the fruit juice. Variability in taste and colour of fruits is mostly due to changes in contents and ratios of sugar (Doyon et al., 1991).

The morphological characteristics of fruit in Pyrus genotypes are variable with respect to genetics and environments. To meet the need for more food and provide reservoir of genetic variation to the breeders for finding particular characters such as resistance genes for diseases, pests and for adaptation to wider ecological conditions, it will be necessary to make better use of a broader range of the world's plant genetic diversity. Genetic variability studies provide basic information regarding the genetic properties of the population based on which breeding methods are formulated for further improvement of the crop (Yadav et al., 2014). However, (Khan et al., 2015) reported that genetic variability is a basic information needed for the breeders to improve the crops by adopting appropriate method of selection based on variability that exist in the material. Evidences exist that the germplasm resources of fruit plants are threatened to extinction (Bennett, 1965; Frankel, 1975). Such reductions have serious implication for food security in the long term. Therefore, conservation and sustainable use of genetic resources is important to meet the demand for future food security. The wide diversity of the pear genotypes has great variability in their fruit quality. Therefore, characterization for all existing variation within genotypes is of vital importance.

\section{Materials and Methods}

The present investigation was carried out during the year 2016-17 and 2017-18 at different selected pear growing areas of Jammu province. The study area lies in Doda and kishtwar district. The Doda district lies between $32^{\circ} 53^{\prime}$ and $34^{\circ} 21^{\prime} \mathrm{N}$ latitude and $75^{\circ} 1^{\prime}$ and $76^{\circ} 47^{\prime} \mathrm{E}$ longitude. It has an average elevation of 1107 meters (3361 feet) from mean sea level. The Kishtwar district lies in the north-east corner of Jammu region between $33^{\circ} 19^{\prime} 12^{\prime \prime} \mathrm{N}$ and $75^{\circ} 46^{\prime} 12^{\prime \prime} \mathrm{E}$ coordinates. Kishtwar is located at a height of $1640 \mathrm{~m}$ above $\mathrm{msl}$ and is about $232 \mathrm{Kms}$ from Jammu. Survey was done from major pear growing districts viz., Doda and Kishtwar district of Jammu province of Jammu and Kashmir state, to select promising accession among the diverse pear genotypes and assess variability in their tree morphological characteristics. During the survey to get first hand information local inhabitants and district horticulture offices were consulted about production and 
availability of pear of seedling origin genotypes grown in areas at various places. The location was selected with respect to the availability of diversity in seedling pear genotypes. On the basis of preliminary field observations and interactions with owners, the trees which were bearing extremely small sized, poor quality and low yielding were not included. Finally, plants of sixty (60) seedling origin pear genotypes with divergent tree characters were selected. Codes were allotted to each genotype on the basis of their location (as SKJSPB stands for SKUAST-Jammu soft pear Bhaderwah, SKJSPG stands for SKUAST-Jammu Soft pear Gandoh, SKJSPBH stands for SKUAST-Jammu Soft pear Bhagwa, SKJSPD stands for SKUASTJammu Soft pear Dachhan, SKJSPT stands for SKUAST-Jammu Soft pear Thathri, SKJSPK stands for SKUAST-Jammu Soft pear Kishtwar and SKJSPN stands for SKUAST-Jammu soft pear Nagsani and number were allotted for identification) and geo tagging was done for selected plants. Regular visits were made and observation on different tree characters i.e., tree vigour, tree habit, leaf size, leaf shape and leaf margins were made at different stages of plant growth using different pear descriptors given by NBPGR guidelines recently published in 2000 (NBPGR, 2000). Tree vigour was observed during active growth period rated as 1 (Extremely Weak), 3 (Weak), 5 (Intermediate) , 7 (Vigorous), 9 (Very vigorous). Tree habit was observed during active growth period rated as 3 (upright), 5 (spreading), 7 (drooping).

The leaf size of the plant was observed on mature leaf 3 (small), 5 (medium),7 (large), the leaf shape was observed on mature leaf 1 (ovate- oblong), 2 (orbicular -ovate), 3 (elliptic), 4 (lanceolate), 99 (others) and leaf margins was observed on mature leaf rated as 1(entire), 2 (serrate), 3 (dentate), 4 (serrulate) and 99 (others).

\section{Results and Discussion}

Tree characteristics are very important as far as diversity is concerned. In this study seedling soft pear trees surveyed from different locations showed variability in tree characters. The selections were divided into three categories i.e., upright, spreading and drooping. Out of 60 selections of soft pear 33 (43\%) had upright tree habit, while 19 selections $(32 \%)$ had spreading tree habit and rest of the 8 selections (25\%) had dropping tree habit. On the basis of tree vigour the selections were divided into five categories i.e., extremely weak, weak, intermediate, vigorous and very vigorous. Out of 60 selections of soft pear none of selection had had extremely weak tree vigour, while 1 selections (2\%) had weak tree vigour, 11 selections $(30 \%)$ had intermediate tree vigour, 33 selections $(37 \%)$ had vigorous tree vigour and rest of the 16 selections (32\%) had very vigorous tree vigour. Higher percentage of vigour in seedling trees may be attributed to their genetic constitution and environmental conditions. However tree characteristics viz. tree vigour and tree habit is greatly influenced by location, soil and different cultural practices like training and pruning. It was observed that those trees which were growing under direct sunlight had vigorous growth and produced good quality fruits as compared to those having dense canopies possibly due to more sunlight available for dry matter production. This shows that a great genetic variability exist as for as of vigour of the tree in concerned, in the germplasm of soft pear. In earlier studies also, the Patharnakh trees were recorded to be more vigorous than Leconte and Smith (Gupta and Chohan, 1976) Similarly, Sandhu et al., (2001) also reported vigorous, medium and dwarf soft pear strains on the basis of tree height, spread and trunk girth. Variation in tree habit was also seen among pear genotypes with spreading habit, upright and drooping tree habits (Bhat, 2012). 
Table.1 Tree Characters of indigenous soft pear

\begin{tabular}{|c|c|c|c|c|c|c|c|c|c|c|c|}
\hline S. No & Selection & \multicolumn{2}{|c|}{ Tree habit } & \multicolumn{2}{|c|}{ Tree vigour } & \multicolumn{2}{|c|}{ Leaf size } & \multicolumn{2}{|l|}{ Leaf shape } & \multicolumn{2}{|c|}{ Leaf margin } \\
\hline 1 & SKJSPB-01 & \multicolumn{2}{|c|}{5} & \multicolumn{2}{|c|}{7} & \multicolumn{2}{|l|}{5} & \multicolumn{2}{|l|}{1} & \multicolumn{2}{|c|}{1} \\
\hline 2 & SKJSPB-02 & \multicolumn{2}{|l|}{3} & \multicolumn{2}{|l|}{5} & \multicolumn{2}{|l|}{5} & \multicolumn{2}{|l|}{1} & \multicolumn{2}{|l|}{1} \\
\hline 3 & SKJSPB-03 & \multicolumn{2}{|l|}{7} & \multicolumn{2}{|l|}{7} & \multicolumn{2}{|l|}{7} & \multicolumn{2}{|l|}{2} & \multicolumn{2}{|l|}{4} \\
\hline 4 & SKJSPB-04 & \multicolumn{2}{|l|}{5} & \multicolumn{2}{|l|}{7} & \multicolumn{2}{|l|}{5} & \multicolumn{2}{|l|}{1} & \multicolumn{2}{|c|}{1} \\
\hline 5 & SKJSPG-05 & \multicolumn{2}{|l|}{3} & \multicolumn{2}{|l|}{5} & \multicolumn{2}{|l|}{5} & \multicolumn{2}{|l|}{1} & \multicolumn{2}{|l|}{4} \\
\hline 6 & SKJSPG-06 & 3 & & 5 & & 7 & & 1 & & 4 & \\
\hline 7 & SKJSPG-07 & 7 & & 9 & & 7 & & 1 & & 4 & \\
\hline 8 & SKJSPG-08 & 7 & & 9 & & 7 & & 1 & & 4 & \\
\hline 9 & SKJSPG-09 & 5 & & 5 & & 5 & & 1 & & 4 & \\
\hline 10 & SKJSPG-10 & 7 & & 5 & & 7 & & 1 & & 4 & \\
\hline 11 & SKJSPG-11 & 7 & & 7 & & 7 & & 1 & & 4 & \\
\hline 12 & SKJSPBH-12 & 5 & & 9 & & 5 & & 1 & & 4 & \\
\hline 13 & SKJSPBH-13 & 5 & & 7 & & 5 & & 1 & & 1 & \\
\hline 14 & SKJSPBH-14 & 5 & & 9 & & 7 & & 2 & & 4 & \\
\hline 15 & SKJSPBH-15 & 7 & & 5 & & 5 & & 1 & & 1 & \\
\hline 16 & SKJSPBH-16 & 3 & & 5 & & 5 & & 1 & & 1 & \\
\hline 17 & SKJSPBH-17 & 5 & & 7 & & 5 & & 1 & & 1 & \\
\hline 18 & SKJSPBH-18 & 5 & & 9 & & 7 & & 1 & & 4 & \\
\hline 19 & SKJSPBH-19 & 5 & & 9 & & 7 & & 1 & & 4 & \\
\hline 20 & SKJSPBH-20 & 7 & & 9 & & 3 & & 2 & & 4 & \\
\hline & & Tree habit & Note & Tree vigour & Note & Leaf size & $\begin{array}{c}\text { Not } \\
\text { e }\end{array}$ & Leaf shape & Note & Leaf margin & Note \\
\hline & & Upright & 3 & $\begin{array}{c}\text { Extremely } \\
\text { week }\end{array}$ & 1 & Small & 3 & ovate & 1 & Entire & 1 \\
\hline & & Spreading & 5 & weak & 3 & Medium & 5 & ovate oblong & 2 & Serrate & 2 \\
\hline & & Drooping & 7 & intermediate & 5 & Large & 7 & Orbicular ovate & 3 & Dentate & 3 \\
\hline & & & & vigorous & 7 & & & Elliptic & 4 & Serrulate & 4 \\
\hline & & & & very vigorous & 9 & & & Lanceolate & 99 & Others & 99 \\
\hline
\end{tabular}




\begin{tabular}{|c|c|c|c|c|c|c|c|c|c|c|c|}
\hline \multicolumn{12}{|c|}{ Table.1 Continuation.... } \\
\hline S. No & Selection & \multicolumn{2}{|l|}{ Tree habit } & \multicolumn{2}{|c|}{ Tree vigour } & \multicolumn{2}{|l|}{ Leaf size } & \multicolumn{2}{|l|}{ Leaf shape } & \multicolumn{2}{|l|}{ Leaf margin } \\
\hline 21 & SKJSPBH-21 & \multicolumn{2}{|l|}{3} & \multicolumn{2}{|l|}{7} & \multicolumn{2}{|l|}{5} & \multicolumn{2}{|l|}{2} & \multicolumn{2}{|l|}{4} \\
\hline 22 & SKJSPD-22 & \multicolumn{2}{|l|}{3} & \multicolumn{2}{|l|}{5} & \multicolumn{2}{|l|}{5} & \multicolumn{2}{|l|}{3} & \multicolumn{2}{|l|}{4} \\
\hline 23 & SKJSPD-23 & \multicolumn{2}{|l|}{5} & \multicolumn{2}{|l|}{5} & \multicolumn{2}{|l|}{5} & \multicolumn{2}{|l|}{3} & \multicolumn{2}{|l|}{2} \\
\hline 24 & SKJSPD-24 & \multicolumn{2}{|l|}{3} & \multicolumn{2}{|l|}{7} & \multicolumn{2}{|l|}{5} & \multicolumn{2}{|l|}{3} & \multicolumn{2}{|l|}{2} \\
\hline 25 & SKJSPD-25 & \multicolumn{2}{|l|}{7} & \multicolumn{2}{|l|}{7} & \multicolumn{2}{|l|}{5} & 3 & & 2 & \\
\hline 26 & SKJSPD-26 & 3 & & 7 & & 5 & & 3 & & 2 & \\
\hline 27 & SKJSPD-27 & 3 & & 7 & & 5 & & 3 & & 4 & \\
\hline 28 & SKJSPD-28 & 3 & & 7 & & 5 & & 3 & & 4 & \\
\hline 29 & SKJSPD-29 & 3 & & 7 & & 5 & & 3 & & 4 & \\
\hline 30 & SKJSPD-30 & 3 & & 9 & & 5 & & 3 & & 4 & \\
\hline 31 & SKJSPD-31 & 3 & & 7 & & 7 & & 3 & & 4 & \\
\hline 32 & SKJSPD-32 & 3 & & 9 & & 7 & & 3 & & 4 & \\
\hline 33 & SKJSPD-33 & 3 & & 7 & & 5 & & 3 & & 4 & \\
\hline 34 & SKJSPD-34 & 7 & & 9 & & 7 & & 3 & & 4 & \\
\hline 35 & SKJSPD-35 & 7 & & 9 & & 7 & & 3 & & 4 & \\
\hline 36 & SKJSPD-36 & 5 & & 9 & & 7 & & 3 & & 4 & \\
\hline 37 & SKJSPT-37 & 5 & & 9 & & 7 & & 3 & & 4 & \\
\hline 38 & SKJSPT-38 & 5 & & 9 & & 7 & & 3 & & 2 & \\
\hline 39 & SKJSPT-39 & 5 & & 9 & & 5 & & 3 & & 2 & \\
\hline 40 & SKJSPT-40 & 5 & & 5 & & 5 & & 3 & & 2 & \\
\hline & & Tree habit & Note & Tree vigour & Note & Leaf size & Note & Leaf shape & Note & Leaf margin & Note \\
\hline & & Upright & 3 & $\begin{array}{l}\text { Extremely } \\
\text { week }\end{array}$ & 1 & Small & 3 & ovate & 1 & Entire & 1 \\
\hline & & Spreading & 5 & weak & 3 & Medium & 5 & ovate oblong & 2 & Serrate & 2 \\
\hline & & Drooping & 7 & intermediate & 5 & Large & 7 & Orbicular ovate & 3 & Dentate & 3 \\
\hline & & & & vigorous & 7 & & & Elliptic & 4 & Serrulate & 4 \\
\hline & & & & very vigorous & 9 & & & Lanceolate & 99 & Others & 99 \\
\hline
\end{tabular}




\begin{tabular}{|c|c|c|c|c|c|c|c|c|c|c|c|}
\hline S. No & Selection & \multicolumn{2}{|c|}{ Tree habit } & \multicolumn{2}{|c|}{ Tree vigour } & \multicolumn{2}{|c|}{ Leaf size } & \multicolumn{2}{|l|}{ Leaf shape } & \multicolumn{2}{|c|}{ Leaf margin } \\
\hline 41 & SKJSPT-41 & \multicolumn{2}{|c|}{3} & \multicolumn{2}{|l|}{5} & \multicolumn{2}{|l|}{5} & \multicolumn{2}{|l|}{3} & \multicolumn{2}{|c|}{2} \\
\hline 42 & SKJSPT-42 & \multicolumn{2}{|l|}{3} & \multicolumn{2}{|l|}{7} & \multicolumn{2}{|l|}{7} & \multicolumn{2}{|l|}{3} & \multicolumn{2}{|c|}{2} \\
\hline 43 & SKJSPK-43 & \multicolumn{2}{|l|}{7} & \multicolumn{2}{|l|}{7} & \multicolumn{2}{|l|}{5} & \multicolumn{2}{|l|}{3} & \multicolumn{2}{|c|}{4} \\
\hline 44 & SKJSPK-44 & \multicolumn{2}{|l|}{7} & \multicolumn{2}{|l|}{9} & \multicolumn{2}{|l|}{5} & \multicolumn{2}{|l|}{3} & \multicolumn{2}{|c|}{4} \\
\hline 45 & SKJSPK-45 & \multicolumn{2}{|l|}{3} & \multicolumn{2}{|l|}{7} & & & & & \\
\hline 46 & SKJSPK-46 & \multicolumn{2}{|l|}{7} & \multicolumn{2}{|l|}{7} & 7 & & 2 & & & \\
\hline 47 & SKJSPK-47 & 3 & & 5 & & 5 & & 3 & & & \\
\hline 48 & SKJSPK-48 & 3 & & 7 & & 3 & & 1 & & & \\
\hline 49 & SKJSPP-49 & 7 & & 5 & & 7 & & 4 & & & \\
\hline 50 & SKJSPC-50 & 7 & & 5 & & 5 & & 3 & & & \\
\hline 51 & SKJSPC-51 & 3 & & 2 & & 3 & & 1 & & & \\
\hline 52 & SKJSPC-52 & 3 & & 7 & & 3 & & 1 & & & \\
\hline 53 & SKJSPC-53 & 3 & & 5 & & 3 & & 2 & & & \\
\hline 54 & SKJSPC-54 & 3 & & 7 & & 3 & & 1 & & & \\
\hline 55 & SKJSPGA-55 & 3 & & 5 & & 5 & & 3 & & & \\
\hline 56 & SKJSPN-56 & 5 & & 5 & & 5 & & 3 & & & \\
\hline 57 & SKJSPN-57 & 5 & & 9 & & 7 & & 3 & & & \\
\hline 58 & SKJSPN-58 & 5 & & 9 & & 5 & & 3 & & & \\
\hline 59 & SKJSPN-59 & 3 & & 5 & & 5 & & 3 & & & \\
\hline 60 & SKJSPN-60 & 5 & & 9 & & 7 & & 3 & & & \\
\hline & & $\begin{array}{l}\text { Tree } \\
\text { habit }\end{array}$ & Note & Tree vigour & Note & Leaf size & Note & Leaf shape & Note & Leaf margin & Note \\
\hline & & Upright & 3 & Extremely week & 1 & Small & 3 & ovate & 1 & Entire & 1 \\
\hline & & Spreading & 5 & weak & 3 & Medium & 5 & ovate oblong & 2 & Serrate & 2 \\
\hline & & Drooping & 7 & intermediate & 5 & Large & 7 & Orbicular ovate & 3 & Dentate & 3 \\
\hline & & & & vigorous & 7 & & & Elliptic & 4 & Serrulate & 4 \\
\hline & & & & very vigorous & 9 & & & Lanceolate & 99 & Others & 99 \\
\hline
\end{tabular}


Table.2 Frequency of tree characters of indigenous soft pear

\begin{tabular}{|c|c|c|c|}
\hline Tree characteristics & Category & Number of selections & Frequency Percentage \\
\hline \multirow[t]{4}{*}{ Type of planting material } & Seedling & 60 & 100 \\
\hline & Layered & - & - \\
\hline & grafted & - & \\
\hline & Others & - & - \\
\hline \multirow[t]{3}{*}{ Tree habit } & upright & 33 & 43 \\
\hline & spreading & 19 & 32 \\
\hline & drooping & 8 & 25 \\
\hline \multirow[t]{5}{*}{ Tree vigour } & Extremely weak & 0 & - \\
\hline & weak & 1 & 2 \\
\hline & intermediate & 11 & 30 \\
\hline & vigorous & 33 & 37 \\
\hline & very vigorous & 16 & 32 \\
\hline \multirow[t]{3}{*}{ Leaf size } & small & 6 & 10 \\
\hline & medium & 32 & 53 \\
\hline & large & 22 & 37 \\
\hline \multirow[t]{5}{*}{ Leaf shape } & ovate & 21 & 35 \\
\hline & ovate oblong & 6 & 10 \\
\hline & Orbicular ovate & 31 & 52 \\
\hline & Elliptic & 1 & 2 \\
\hline & lanceolate & 0 & - \\
\hline \multirow[t]{5}{*}{ Leaf margin } & Entire & 8 & 13 \\
\hline & Serrate & 9 & 15 \\
\hline & Dentate & - & - \\
\hline & Serrulate & 43 & 72 \\
\hline & others & - & - \\
\hline
\end{tabular}


Leaves play an important role in plant growth and development as leaves are the part of plant which serves as a source of food to the plants. Out of 60 selections of soft pear 6 (10 $\%)$ selections having small leaf size, while 32 selections (53\%) having medium leaf size and rest of the 22 selections (37\%) having large leaf size. In case of leaf shape $21(35 \%)$ selections had ovate shape of leaf, $6(10 \%)$ selections had ovate oblong shape of leaf, $31(52 \%)$ selections had orbicular ovate shape of leaf, 1 (2\%) selections had elliptic shape of leaf, and no selections had lanceolate shape of leaf. Out of 60 selections under study 8 (13 $\%)$ selections had entire leaf margins, $0(0 \%)$ selections had dentate leaf margins, 43 (72\%) selections had serrulate leaf margins and 0 $(0 \%)$ selections had others margins of leaves.

The variability with respect to leaf size in different soft pear selections might be due to their genetic makeup and interaction with the environment. A study carried out by Elshihy et al., 2004 reported that leaves are serrated and the leaf index (leaf width/leaf length) ranged from 0.35 to 0.78 in Syrian pear genotypes. Bist et al., (2003) reported that Gola gave significantly higher leaf length as compared to Patharnakh in early maturing group. Singh (2006) reported maximum leaf breadth in Strain III and VIII and minimum in Strain XI. Pear selections exhibited quantitative diversity in foliar dimensions as significant differences were found among them as reported by Ahmed (2008). Hassan et al., 2017 show variation with leaf characters. Incisions of margins as bicrenate in $18.18 \%$, serrate type 1 in $24.24 \%$, serrate type 2 in $15.15 \%$ and biserrate in $42.42 \%$ accessions.

The North western Himalayan region is one of the richest and most diverse gene pool of the cultivated pear. The success of any breeding programme depends on the presence of sufficient genetic variability to pursue effective selection. It is necessary to assess the relative magnitude of the existing genetic diversity in order to use such information together with other selection parameters for the improvement of fruit yield and other quality parameters of any fruit crop through adoption of an effective breeding approach. The extent of genetic variability indicates the potential of exercising selection of a particular genotype. Knowledge of the extent of diversity for tree phenology traits in pear populations (seedling origin) and subsequent identification of adapted superior genotypes/cultivars as potential donors for yield will serve as pertinent source of superior parents for further breeding programme in pear.

\section{References}

Ahmed, M. 2008. Biodiversity in pears (Pyrus spp.): Characterization and conservation of germplasm from Azad Jammu and Kashmir. Ph. D. thesis submitted to Department of Horticulture University College of Agriculture Bahauddin Zakariya UniversityMultan.

Ahmed, M., Anjum, M.A., Shinwari, K.Z., Awan, M.S.and Rabbani, M.A. 2011. Assessment of fruit quality parameters of Pyrus germplasm collected from Azad Jammu and Kashmir (Pakistan). Pakistan Journal of Botany 43(2): 971981

Bennett, E. 1965. Plant introduction and genetic conservation: Genecological aspects of an urgent world problem. Scottish Plant Breeding Station Records, pp. 27-113.

Bhat, Z. A. 2012. Molecular characterization and hybridization studies in pear. Ph. D. Thesis submitted to Division of Pomology, Punjab Agriculture University, Ludhiana.

Bist, L.D., Yadav, A. and Prakash, C. 2003. Performance of low chill pear cultivars under sub mountainous Tarai region. 
Progressive Horticulture 35: 20-24.

Blattny, C. 2003. Pears. In: Caballero, B., Trugo, L.C. and Finglas, P.M. (Eds.). Encyclopedia of Food Sciences and Nutrition. Academic Press, London, pp. 4428-4433

Challice, J. and M. Westwood. 2008. Numerical taxonomic studies of the genus Pyrus using both chemical and botanical characters. Botanical Journal of the Linnean Society, 67 (2): 121-148

Doyon, G., Gaudreau, G., St. Gelais, D., Beaulieu, Y. and Randall, C.J. 1991. Simultaneous HPLC determination of organic acids, sugars and alcohols. Canadian Institute of Science and Technology Journal, 24: 87-94.

Elshihy, O.M., Sharaf, A.N. and Muzher, B.M. 2004. Morphological, anatomical and biochemical characterization of Syrian Pear (Pyrus syriaca Boiss) genotypes. Arabian Journal of Biotechnology 7(2):209- 218

Frankel, O. H. 1975. Genetic resources survey as a basis for exploration. In: Today and Tomorrow (Eds. Frankel, O.H. and Hawkes, J.G.). Cambridge University
Press, UK, pp. 99-109.

Gupta, M.R. and Chohan, G.S. 1976. Performance of pear cultivars at Bahadurgah. Punjab Hort. J. 16: 115-20 Khan, H. Viswanatha, K. P. and Sowmya, H. C. 2015. Study of genetic variability parameters in cowpea (Vigna vnguiculata L. Walp.) germplsam lines. The Bioscan. 10(2): 747-750.

Sandhu, A.S., Singh, T., Singh, R., Dhillon, W.S. and Sharma, K.K. 2001. Evaluation of sub- tropical germplasm. Indian J. Plant Genet. Resour. 14 : 209 11

Singh, B. 2006. Vegetative and fruiting behaviour of hard pear strains in relation to nutrient status. Ph.D. dissertation, Punjab Agriculture University, Ludhiana

Yadav, R. Rana, J. C. and Ranjan, J. K. 2014. Analysis of variability parameters for morphological and agronomic traits in grain amaranth (Amaranthus sp) genotypes. The Bioscan. 9(4): 16611665.

\section{How to cite this article:}

Ambika Bhandari, V. K. Wali, Amit Jasrotia, Mahital Jamwal, Kiran Kour, Gurdev Chand, Vivak M Arya and Razdan, V. K. 2020. Diversity for Tree Growing Habit in the Natural Population of Indigenous Soft Pear in Jammu Province, India. Int.J.Curr.Microbiol.App.Sci. 9(06): 4171-4179. doi: https://doi.org/10.20546/ijcmas.2020.906.488 